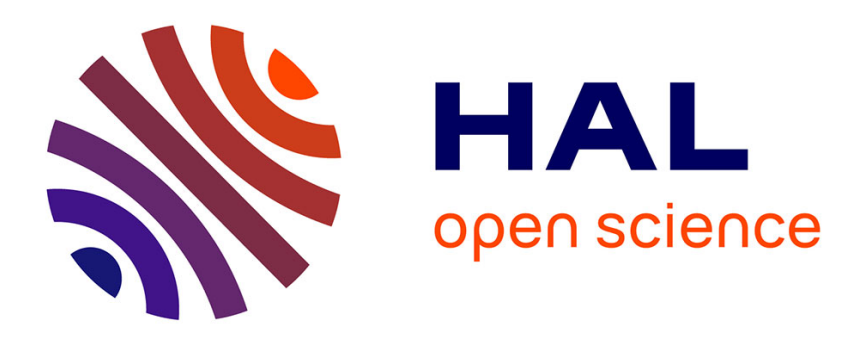

\title{
Indifference Curves and the Ordinalist Revolution
}

Jean-Sébastien Lenfant

\section{To cite this version:}

Jean-Sébastien Lenfant. Indifference Curves and the Ordinalist Revolution. History of Political Economy, 2012, 44 (1), pp.113 - 155. 10.1215/00182702-1504077 . hal-01771855

\section{HAL Id: hal-01771855 \\ https://hal.science/hal-01771855}

Submitted on 19 Apr 2018

HAL is a multi-disciplinary open access archive for the deposit and dissemination of scientific research documents, whether they are published or not. The documents may come from teaching and research institutions in France or abroad, or from public or private research centers.
L'archive ouverte pluridisciplinaire HAL, est destinée au dépôt et à la diffusion de documents scientifiques de niveau recherche, publiés ou non, émanant des établissements d'enseignement et de recherche français ou étrangers, des laboratoires publics ou privés. 


\title{
Indifference Curves and the Ordinalist Revolution
}

\author{
Jean-Sébastien Lenfant
}

Joseph Schumpeter, as a spoilsport (and probably under Paul Samuelson's influence), looked pessimistically upon the internal coherence and methodological progress achieved by the ordinalist revolution:

If [the ordinalists] use nothing that is not observable in principle, they do use "potential" observations which so far nobody has been able to make in fact: from a purely practical standpoint we are not much better off when drawing purely imaginary indifference curves than we are when speaking of purely imaginary utility functions. (Schumpeter 1954, 1067)

Schumpeter actually raised a methodological issue more than a practical one. Indeed, once Vilfredo Pareto had faded from the scene, the status ${ }^{1}$ of indifference curves within demand theory was rarely discussed for its own sake by the main protagonists of the ordinalist revolution.

Correspondence may be addressed to Jean-Sébastien Lenfant, CLERSE, Faculté de sciences économiques et sociales, Université Lille 1, Cité Scientifique, 59655 Villeneuve d'Ascq; e-mail: jean-sebastien.lenfant@univ-lille1.fr. I would like to acknowledge the helpful detailed comments of Philippe Mongin and Ivan Moscati, as well as the suggestions from Pierre Lacour and an anonymous referee.

1. By "status," it is meant here that indifference curves can be looked upon either as an experimental construction or as an observational construction (derived from constrained choice), or else as a concept based upon introspection or other theoretical arguments. Indeed, one can imagine that "status" refers to the origin of indifference curves, including the semantics of the concept.

History of Political Economy 44:1 DOI 10.1215/00182702-1504077

Copyright 2012 by Duke University Press 
It was generally relegated to footnotes and asides, whereas other issues such as integrability (Samuelson 1950; Houthakker 1950; Chipman et al. 1971), the measurement of utility (Frisch 1926; Schultz 1933; Frisch 1932; Lange 1934), and complementarity (Johnson 1913; Slutsky 1915; Hicks and Allen 1934; Samuelson 1974) were discussed at length.

The concept of the indifference curve was the touchstone of the escape from cardinalism and the psychological foundations of demand and choice. ${ }^{2}$ Yet, once Hendrik S. Houthakker (1950) and Paul Samuelson (1950) recognized that the whole theory of the consumer could be derived from the strong axiom of revealed preferences (without supposing the existence of indifference curves from the outset), indifference curves survived mainly, if not exclusively, because they made it easy to teach and learn certain ideas and principles involving choices between certain prospects (intertemporal choice, the leisure-consumption trade-off). For such a role it is endowed with convenient mathematical properties allowing for the use of duality theorems.

Thus, the indifference curve went from being held in high esteem to being of secondary importance, once the strong axiom of revealed preferences was developed. How and when did this hierarchical about-face take place? The question does not seem to have caught the interest of historians. It is often alleged that the construction of experimental indifference curves was on Pareto's agenda. ${ }^{3}$ Even this is a simplistic analysis of Pareto, and to the best of our knowledge, there have been no attempts to recount in a broad way the story of indifference curves within the ordinalist revolution. ${ }^{4}$ As elsewhere with the development of the theory of choice, the 1930s and 1940s resulted in the stabilization of the concept of the indifference curve. Actually, it must be stressed that

2. More precisely, what is meant here is the escape from a certain kind of psychology that was widespread in the late nineteenth century and the beginning of the twentieth century, that is, psychological assumptions taken from psychophysiology and experimental psychology and whose main figures were (or had been) Helmholtz, Weber, Fechner, and Wundt.

3. "Pareto, having replaced the assumption of utility with the assumption of indifference curves, went one step further to suggest that, in principle, economists could replace the assumption of indifference curves with an experimental derivation of indifference curves" (Gross and Tarascio 1998, 171). As will be seen, this assertion is misleading and does not reflect adequately Pareto's own ideas about indifference curves. A different point of view can be found in Moscati 2007a.

4. The question of the status of indifference curves within the history of consumer demand has been tackled only indirectly or partially in some recent articles either in relation to integrability (Hands 2006) or in relation to the history of experimental economics (Moscati 2007a) and rational behavior (Giocoli 2003). 
the status of indifference curves within the theory of choice is usually regarded as depending upon much deeper issues such as the measurement of utility, the integrability of demand, and the definition of complementarity.

Nevertheless, it would be unfair to regard views on indifference curves within the ordinalist revolution solely as by-products of other theoretical debates. ${ }^{5}$ The question was occasionally treated for its own sake, and one can find here and there incidental remarks about the possibility, necessity, and usefulness of building the theory of demand upon experimental indifference curves. As regards this more specific issue, a number of arguments were raised in the 1930s and early 1940s in favor of a theoretical and nonexperimental status of indifference curves. The central piece of work that catalyzed the debate was Louis L. Thurstone's experimental derivation of an indifference map in 1931. Mainly, the decade following Thurstone's experiment sealed the status of indifference curves within demand theory: they became useful only for their pedagogical and heuristic properties.

At the beginning of this story are Henry Schultz, Harold Hotelling, and Milton Friedman, who were engaged in reconciling empirical demand studies and the Paretian theory of demand and utility. At the end of the story, one can consider W. Allen Wallis and Friedman's 1942 article as the most influential criticism of the experimental nature of indifference curves and Samuelson's theory of revealed preferences (e.g., Samuelson 1938a, 1930b, 1950) as the final plea for a theoretically observational concept of indifference curves. By the end of the 1940s, no economist would appeal seriously to any kind of naive experimental derivation of

5. Integrability, measurement, and complementarity all concern "deeper" questions, with an immediate concern for the robustness and fruitfulness of the theory, i.e., the very existence and nature of the utility function. In the two-good case, we start with these questions more or less answered with the notable exception of complementarity (Lenfant 2006) and then use indifference curves to represent the utility function. Thus, the methodological problems that the indifference curve involves are of a different nature than those that integrability, measurement, and complementarity involve. In the two-good case, if we assume that we can use indifference curves, then (1) we have already assumed a solution to the integrability problem; (2) we can use the curves to give one answer to the measurability question (utility is ordinal: the numbers attached to the indifference curves do not affect the choices that the consumer makes); and (3) we can learn (as Fisher and Pareto failed to learn) that we cannot really say anything much about complementarity. Of course, in the three-good case, the question of the status of the indifference surfaces is more on an equal footing with integrability, measurement, and complementarity. Yet, it was rather considered as a secondary problem, more methodological than theoretical. See also section 6. 
indifference curves as a way to derive individual or aggregate demand functions. ${ }^{6}$

The aim of this article is to show how the concept of the indifference curve was progressively stabilized within demand theory. Section 1 deals with the foundations of choice theory in the Paretian tradition. Section 2 gives some insights about the revival of the Paretian school in the United States in the 1930s. Thurstone's experiment is presented in section 3, and its reception by economists is the subject of section 4 . Section 5 concentrates on Wallis and Friedman's 1942 article, which represented one challenge to indifference curves. Section 6 deals with the other challenge to indifference curves, Samuelson's theory of revealed preferences. The conclusion gives some insights into the experimental or observational status of indifference curves in the 1940s and after.

\section{Indifference Curves within the Paretian School}

Our aim here is to grasp some specific aspects of demand theory in relation to indifference curves, as they have been dealt with from Pareto onward and as they were understood in America in the late 1920s and early 1930s. Before entering into this story, it seems necessary to say a word about the ordinalist revolution and about the English contributions to ordinalism.

The ordinalist revolution originates in the criticism of the psychological foundations of the theory of demand, namely, the principle of decreasing marginal utility as Alfred Marshall ([1890] 1898) used it. The rejection of hedonist hypotheses led Irving Fisher (1892) and Pareto (1896-97, 1900, 1909) to favor an objective or "positive" approach to economic concepts. The "ordinalist revolution" (Omarzabal 1995, 116) is grounded in a methodological transformation of economics that put the facts of objective experience as a foundation of economics and provided a research program for the ensuing years (Green and Moss 1993; Lewin 1996). ${ }^{7}$ Mathemati-

6. Ivan Moscati (2007a) has shown that a revival in economic experiments on consumer choice would take place later in the 1950s and 1960s. But the theoretical stakes at the time were quite different, and Moscati devotes only a few lines to the most natural extension of experimental work on pure consumer theory, that is, stochastic choice and binary choice. Indeed, work in that field did not bear much on the development of experiments on consumer behavior.

7. Historians have pointed out that ordinalism and the escape from psychology are two different things. According to Shira B. Lewin (1996), Pareto and Fisher can be classified as "psychological ordinalists" (as opposed to "psychological hedonists") because preferences still have a hidden psychological meaning to them. Luigino Bruni and Francesco Guala 
cally, ordinalism is entirely based upon the idea that one can dispense with the use of a specific utility function and that no meaning shall be attached to utility measurement, except as an ordinal principle.

Clearly, the development of ordinalism must be separated from the introduction of the concept of the indifference curve. Ordinalism was first advocated in Fisher's “Mathematical Investigations" (1892) and Pareto's Sunto (1900) and Manual ([1909] 1971), while the indifference curve had appeared in F. Y. Edgeworth's Mathematical Psychics (1881). It was thus only through Fisher's and Pareto's recasting that the concept of the indifference curve became irreversibly associated with the promotion of ordinalism. ${ }^{8}$ Along the way, the recasting of the theory of choice along ordinalist lines raised a number of issues (about integrability, measurability, and complementarity) that would be progressively settled. A reasonable closing date for the ordinalist revolution is 1950, after Houthakker's (1950) and Samuelson's (1950) contributions. ${ }^{9}$

From the late 1920s, the Paretian school was progressively gaining a larger audience while the use of the concept of marginal utility and other derivative concepts was challenged. Consequently, demand theory was recast along the principles of individual preferences and ordinal utility functions. ${ }^{10}$ Nevertheless, English authors proved very silent about the meaning of indifference curves. Most if not all of the reflections after 1920 about the nature of indifference curves took place in America, mainly under the impulse of Henry Schultz at Chicago. This is an American story. ${ }^{11}$

(2001) have convincingly applied this idea to Pareto's writings. It is true that ordinalism, taken in a very strict sense (that of using an index utility function), does not imply that psychological arguments are abandoned. We nevertheless argue that this formal opposition between psychological hedonists and psychological ordinalists might be exaggerated as long as one does not discuss precisely what kind of psychological assumptions or statements can be used in economics. Ordinalism would never have been promoted if theoreticians had not felt too much constrained with the main assumptions of hedonism. Thus, with all due care, ordinalism and the escape from psychology have been fellow travelers, and this is what is usually meant by the phrase "ordinalist revolution."

8. Moreover, Fisher $(1891,4)$ discovered the concept of the indifference curve apparently independently from Edgeworth, thus showing that it was just a tool that could be used either in a cardinal or in an ordinal context.

9. Hicks and Allen (1934) had done most of the job but not finished it. Along the way, the main protagonists of this story (other than those already mentioned) are Johnson (1913), Slutsky (1915), Schultz (1938), Friedman (1933), Little (1949), and Georgescu-Roegen (1936). For more on Johnson, Slutsky, et al., see Stigler 1950.

10. Parts of this story can be found in Chipman 1976, Hands and Mirowski 1998, Chipman and Lenfant 2002, Hands 2006, and Lenfant 2006.

11. We will discuss this assertion at beginning of the next section. 
As is well known, Pareto's and Fisher's main idea was that knowledge of observed behavior was enough to derive the equilibrium of markets and the laws of a market economy. This idea was based upon the intuition that indifference curves were in principle obtainable from observed behavior and that indifference maps could be represented by indexing utility functions. Consequently, they expected to ignore the psychological foundations of choice and of price theory. ${ }^{12}$

It would take too long to enter precisely into Fisher's and Pareto's ideas about psychology. However, one or two aspects must be mentioned here briefly. Pareto ([1909] 1971, 29) and Fisher $(1892,5)$ showed a common reluctance toward a psychological foundation of utility, even though Pareto was rather looking for a temporary separate development of economics and psychology. Psychology at the time was considered as the science of psychical phenomena and sensations, and to some extent it was associated with the developments of psychophysics, which is a branch of psychology dealing with the measurement of mental states in relation to external stimuli. ${ }^{13}$ It is thus interesting to see how Fisher and Pareto justified the construction of indifference curves and the existence of a utility index. Both seemed to believe that experimentation was impossible in practice but possible in theory. Fisher $(1892,67-68)$ suggested a "metaphoric" experiment, by which an individual would be asked to determine his consumption bundle and then, fixing the quantity of all goods but two, he would be asked to modify his combination of the two goods in order to keep the same level of utility. Nevertheless, in

12. From the outset, we want to clear up any misunderstanding about the link between an analytical tool (indifference curves) and the escape from psychology (the abandonment of psychophysical assumptions). The simple fact of using indifference curves is not a plea against cardinalism. Indeed, Edgeworth, a founding father of indifference curves, was an unrepentant cardinalist. In fact, most if not all of his arguments about the use of indifference curves as a cardinalist concept are only possible once one compares two indifference curves for the same individual. So, it must be clear that I am not pointing out any contradiction per se between psychology and indifference curves. I am only stressing that indifference curves would be exploited in order to promote an ordinalist representation of utility and a behaviorist foundation for the theory of choice and demand.

13. As far as we know, neither Pareto nor Fisher ever commented on current developments in psychology. In the Manual, Pareto ([1909] 1971, chap. 4, para. 33) mentions Fechner, Delbœuf, and Wundt in a footnote. Those works are mentioned only as references for the Weber-Fechner law of decreasing satisfaction. We can only speculate about Pareto's acquaintance with Wundt's theory presented in his Grundzüge der physiologischen Psychologie. Wundt was then the most important experimental psychologist, and he had shown that simple laws of the WeberFechnerian type (psychophysical or associative laws) could not apply to most psychological phenomena, which are governed by apperception (Lachelier 1885; Boring 1950, chap.16). 
the end Fisher never relied on any kind of experiment, and he eventually derived the shape of indifference curves from the properties of demand that he attached to the extreme cases of perfect substitutes and perfect complements (71).

Pareto's own construction and discussion of indifference curves is developed in the Manual..$^{14}$ There he used the word experiment in a broad and fluctuating sense. On many occasions, Pareto ([1909] 1971) suggested finding individual indifference curves "by experiment," and he indicated many ways to achieve that task. For instance, Pareto referred to a hypothetical experiment bearing directly on tastes (391-92), whereas elsewhere he suggested constructing indifference curves from observed choices for different incomes and prices (414-16). He knew that experiments would not permit one to obtain the differential equation of an indifference curve but only the ratio of marginal utilities at a point. He ended with the idea that economists should be content with virtual experiments: "The fairly great difficulty, the impossibility even, that may be found in carrying out these experiments in practice, is of little importance; their theoretical possibility alone is enough to prove, in the cases which we have examined, the existence of the indices of ophelimity, and to reveal certain of their characteristics" (415; my italics).

So, the final methodological position of Pareto is that the theoretical possibility of an empirical construction of indifference curves is at least enough for the foundation of the theory of choice..$^{15}$ Eventually, when he comes to a precise description of indifference curves, Pareto appeals to "every day experience" and to introspection to discuss the shape of indifference curves (572). ${ }^{16}$ In this respect, it is of the utmost importance to keep in mind what indifference curves are supposed to be as theoretical

14. Pareto ([1900] 2008) already argued that indifference curves could be obtained through experiments or statistical studies. As long as statisticians have not established lines of indifference, "for lack of more precise notions, the science possesses only some general data suggested by crude and everyday observations of facts" (478).

15. It does not prevent one from appealing to psychological arguments in the field of applied economics (Bruni and Guala 2001).

16. Introspection in utility theory is usually-and incorrectly-associated with the use of psychological arguments. Introspection is actually a method, whereas psychology is the study of perceptions and representations. Introspection as a method of investigation has been challenged in economics as well as in psychology. Now, the fact is that Fechner did use introspection whereas Wundt rejected it. More generally, Pareto ([1909] 1971, chap. 3, para. 31) always maintained that the methodology of economics could not be modeled on the methodology of physics, and that any economic theory must be regarded as a method of search rather than as a method of demonstration. 
constructs. Pareto never meant that indifference curves are the visual description of a mental state of mind regarding tastes at a given instant of time. On the contrary, he insisted again and again in the Manual that the description of individual tastes is about stabilized tastes, as they can be derived from repeated acts of choice in a context of stable economic conditions:

We will study the many logical, repeated actions which men perform to procure the things which satisfy their tastes. . . . In other words, we are concerned only with certain relations between objective facts and subjective facts, principally the tastes of men. Moreover, we will simplify the problem still more by assuming that the subjective fact conforms perfectly to the objective fact. This can be done because we will consider only repeated actions to be a basis for claiming that there is a logical connection uniting such actions. A man who buys a certain food for the first time may buy more of it than is necessary to satisfy his tastes, price taken into account. But in a second purchase he will correct his error, in part at least, and thus little by little, will end up by procuring exactly what he needs. We will examine this action at the time when he has reached this state. Similarly, if at first he makes a mistake in his reasoning about what he desires, he will rectify it in repeating the reasoning and will end up by making it completely logical. (103)

Pareto could not have been more explicit. He would come back occasionally to the same idea, notably about the theory of choice, always dismissing any data that were not the result of a reflexive process on the part of the subject. ${ }^{17}$

At this stage, the status of indifference curves remained uncertain, if not contradictory. On the one hand, indifference curves were conceived of as the guarantee for a positivist foundation of demand theory, while on the other hand they were used just as an instrument for proving the existence of an index-utility function. This ambiguity was manifest in the theory of choice from the outset.

From Pareto onward, two lines of thought about utility and demand coexisted and reinforced each other. The dominant line consisted in considering the main properties of indifference curves as given by internal experience and introspection and easily summarized by utility functions,

17. Pareto ([1909] 1971, 105, 123) frequently reminds the reader about this meaning of indifference curves. 
from which general properties of demand could be inferred. The other, less frequent, way of thinking consisted of the idea that indifference curves could be inferred from observed behavior. In accordance with this marginal line of thought, two methods were on offer. The first one consisted of deriving indifference curves from budget data (relating prices, individual incomes, and quantities bought of different goods). ${ }^{18}$ The second one consisted of finding out indifference curves by way of controlled experiments. Indeed, Pareto mentioned both the introspective (dominant) line of thought and the two methods pertaining to the marginal line of thought, and he left it to his followers to discuss their relative merits.

Of course, all these ideas were intermingled to such an extent that most authors were open to different methods. More, it must be stressed that the status of indifference curves appeared as partially dependent upon the debate on the integrability of demand, that is, the possibility of recovering utility functions from observed demand behaviors. ${ }^{19}$ Incidentally, the issue of the status of indifference curves came back in the early 1930 s, in the United States.

\section{The Revival of Paretian Demand Theory in the United States}

The development of the Paretian theory of demand in the 1920s and 1930s took place mainly in the United States and Great Britain. As was pointed out earlier, the status of indifference curves would be discussed in the United States only.

Indeed, as far as English authors are concerned, there was a common reluctance toward discussing the foundations of indifference curves. As a testimony to this, a few words are in order about Edgeworth, Johnson, Allen, and Hicks. Edgeworth, as the inventor of the concept, had a very peculiar purpose in mind. In Mathematical Psychics, "indifference lines" appear only after the presentation of total (generalized) utility functions for each agent and after the formal definition of the "contract curve." Edgeworth introduces indifference curves, defined as the locus of points

18. The idea was to construct indifference curves from a series of budget data under different income-price situations. This project was intimately linked with budget studies and would be promoted by scholars such as Abraham Wald, Jacob Marschak, and René Roy.

19. It is beyond the scope of this article to deal with the history of the integrability issue, which has been well documented elsewhere (see Chipman 1976, Hands 1993, Hands and Mirowski 1998, Chipman and Lenfant 2002, Mongin 2000a and 2000b, and Hands 2006). 
separating the set of exchanges that are acceptable from the set of exchanges that an agent would refuse, in order to demonstrate that the contract curve is really a curve (with no thick part) and can be understood as the result of a series of exchanges between parties. Consequently, indifference curves are derived from the concept of utility (they are not a primary given set of data), and they are devised for a very specific purpose. Johnson (1913) is a good example of the reluctance among English economists to speculate over the semantics of indifference curves, since he takes it as a purely mathematical concept. He probably took the concept from Edgeworth (although he does not adopt the terminology, preferring that of "constant utility curve") and does not even mention Pareto. Indifference curves are simply regarded as a series of convex curves exhibiting different properties about adjacent marginal rates of substitution.

Allen and Hicks (separately and in their joint article as well) manifest no interest either in the semantics or in the methodology attached to indifference curves. For instance, Allen (1934) maintains that indifference curves are simply the expression of constant utility curves, whose various forms indicate various mutual relationships between goods. So, once again, indifference curves are presented as just a mathematical tool (a series of mathematical properties about curvature and adjacent curves) without the slightest word about their methodological foundation. ${ }^{20} \mathrm{In}$ their monumental article, Hicks and Allen (1934) would make only incidental comments on the methodology of the theory of choice (mainly a question of internal coherence). ${ }^{21}$

20. The only exception to this is Allen 1932, in which he argues for the nonintegrability of the field of observed indifference directions. For a comment on Allen's discussion of integrability, see Chipman and Lenfant 2002, 570-73. Note, however, that Allen $(1932,198)$ is skeptical about the possibility of relying on experimentation in economics and of dispensing with psychology: "In the first place, economic experiments under control are almost out of the question, and further, it is difficult in economic theory to prevent the introduction of subjective or psychological elements."

21. Hicks and Allen (1934) take it for granted that indifference curves and surfaces are superior in a heuristic sense to utility functions when studying demand behavior, Giffen goods, and other concepts such as complementarity and independence (in a three-good case at least). Hicks and Allen's justification for the shape of indifference curves is motivated by the simplicity of the assumption, so that the concept of the demand function will be precisely defined (to dispose of any demand correspondence and discontinuity). As is well known, it is based mainly on the idea that the marginal rate of substitution must be decreasing, because it is not falsified in general by experience. Actually Hicks and Allen were not exactly on the same wavelength on this issue (see Chipman and Lenfant 2002). Strange as it may seem, Allen's 1934 article titled "The Nature of Indifference Curves" is nothing but a discussion of their mathematical properties (it does not contain anything about their empirical content). As for Hicks, he would 
More broadly, the idea of linking rational behavior and statistical demand studies is a characteristic of the development of demand theory in America. In Europe, there were disseminated efforts, as we see from Shultz's 1938 book that reviewed them, and almost no connection between the Paretian school, statistical studies, and other kinds of reconstruction (Marco Fanno excepted). ${ }^{22}$ It is quite clear that until 1932, the contributions of Fanno, Ricci, Dominedo, Allen, and Johnson were not oriented by a common set of questions and analytical tools. Things were to change slightly only after the discovery of Slutsky's article. Even the collaboration between Hicks and Allen (1934) appears to have been very brief and led neither to a close convergence on certain important questions (Chipman and Lenfant 2002) nor to statistical studies.

Thus, it is worth concentrating exclusively on the debate among American scientists. The main protagonists of this development are Henry Schultz, Harold Hotelling, and Milton Friedman. Friedman is important for our narrative, to the extent that he took part in the discussion about demand and utility in the United States from the outset and eventually provided influential arguments against an experimental or even empirical derivation of indifference curves (Wallis and Friedman 1942).

Friedman's training in demand theory was shaped by Schultz at Chicago and also by Hotelling at Columbia. A few words about both of them and few others are in order to grasp Friedman's interest and personal commitment to demand theory.

In the late 1920s and early 1930s, the main line of development of the new theory followed the original Paretian ideas, as well as some later contributions in the Paretian spirit, more or less neglected, such as Johnson

improve the argument a little bit in Value and Capital: the decreasing marginal rate of substitution stems from the idea of choice (if people were indifferent between two baskets at the same price, they would not be able to choose; the fact that they make a choice is an argument for convexity). For a more complete discussion of this, see Wong 1978, 36-41; Lenfant 2000, 267-69; and Moscati 2007b, 128-29.

22. Marco Fanno (1926) deserves to be mentioned for his work on the demand for substitutes. Besides, Schultz acknowledged Fanno as the main motivation for his own research program. In his long essay, Fanno did not question the possibility of constructing indifference curves, but he nevertheless introduced an interesting distinction between tastes, as they can be considered in the abstract and as they are practically influenced by economic conditions (income, prices, needs). On this basis he proposed two kinds of indifference curves: indifference curves according to tastes and indifference curves according to consumption (353-54). Nevertheless, the distinction remains very obscure and does not seem to have been mentioned elsewhere. 
1913 and Lenoir 1913. ${ }^{23}$ Slutsky's 1915 article ${ }^{24}$ was still unknown to the main workers in the field. New ideas about utility and demand were introduced progressively within the American academic world, spurred on by Henry Moore and Henry Schultz. Moore and his student Schultz were both involved in the development of theoretical foundations for statistical demand curves, and by the end of the 1920s Schultz's agenda was to improve the derivation of statistical demand curves, basing them on the Paretian theory of choice and utility.

On this occasion, Schultz gave central importance to utility theory for the statistical analysis of demand. Schultz's (1931) idea was that the structural properties of demand were linked to the properties of individual utility functions. In short, Schultz's program was to derive the main laws of "related demand" (demand for related goods) from individual preferences. By referring here and there to utility theory and to the influence of substitution upon demand curves, Schultz showed that the connection of utility theory with the statistical analysis of interdependencies was a promising direction for research. ${ }^{25}$ Around 1930, Schultz $(1931,83)$ was clearly looking in that direction, echoing Pareto's earlier statement: "The properties of the utility functions and indifference curves are very intimately related to certain characteristics of the laws of demand and supply. . . . In [my] opinion, a study of these theoretical relationships [about demand for related goods] will throw a flood of light on the problems connected with the derivation of demand curves from statistics."

Schultz developed this program in two steps between 1932 and 1935, and it must have been at the core of Schultz's discussions with his young student Milton Friedman. Notably, during the winter of 1933, Friedman wrote a draft on demand theory under the title "The Fitting of Indiffer-

23. Apparently, Johnson 1913 and Lenoir 1913 were unknown to American economists. Friedman discovered Lenoir's thesis only during the preparation of his own paper (Friedman 1933). Lenoir's book contains a discussion of the relative slopes of adjacent indifference curves and of the question of satiation, introducing a curve of satiation that would be used later independently by Friedman and Allais.

24. In his famous 1915 article, Slutsky derived the fundamental equations of value, decomposing the price effect on demand into two composite effects (the revenue effect and the substitution effect). Slutsky's analysis was explicitly a continuation of Pareto's theory of utility and demand. A noticeable difference, however, is that Slutsky never mentions indifference curves.

25. In this respect, Schultz acknowledged the influence of Marco Fanno (1933, 164), who developed a correspondence between substitutability as represented with indifference curves, and substitutability as measured through the proportional variation of prices following any external shock on the demand for a good. One can note that Schultz ignores the influence of income distribution upon aggregate demand (see Lenfant 2006). 
ence Curves as a Method of Deriving Statistical Demand Curves." Friedman's often quoted 1933 manuscript is known by economists only indirectly through Schultz's 1938 book, The Theory and Measurement of Demand, where it was partially used in chapters 18 and 19.

Friedman's contribution to Schultz's research program was also reinforced during the year he spent with Hotelling in 1933 at Columbia (the academic year when Schultz was in Europe). Hotelling graduated as a mathematician at Princeton; afterward, he was at the Stanford mathematics department in 1927 and later appointed at Columbia in 1931 (after the early retirement of Moore), where he taught mathematical statistics and mathematical economics. Previously, he had worked with Holbrook Working at the Stanford Food Research Institute, collaborating on the estimation of crop yields, food requirements, amd demand and supply functions for agricultural products (1924-27). He moved gradually to the mathematics department at Stanford before leaving for Columbia (Darnell 1990, 5-7). By the time Friedman arrived at Columbia, Hotelling had already published his famous article on "Edgeworth's taxation paradox" (Hotelling 1932). Edgeworth's paradox deals with the possibility that the imposition of a tax on one good supplied by a monopolist who also supplies a related good (a railway owner supplying first- and second-class travel) may lead to a lowering of the market price of the taxed good.

Hotelling's aim was to understand in depth under what circumstances Edgeworth's paradox might appear. The analysis proceeds within a system of interrelated markets. Thus, one needs to disentangle as far as possible the effects of the interdependence of markets (the system of demand functions) from the influence of specific preferences. The related question is to identify properties of individual preferences that would make the paradox likely or unlikely, and possibly to tell if such preferences are to be met in certain markets. This was the main motivation for his interest for demand analysis, on the basis of the Walras-Pareto framework. ${ }^{26}$

Friedman's 1933 paper echoes the common set of questions asked by Hotelling and Schultz, notably because it shows how experimental or other kinds of empirical knowledge could or should be accounted for within demand theory. The main question raised incidentally is whether,

26. As noted by D. Wade Hands and Philip Mirowski (1998, 352), "Edgeworth produced his counter intuitive numerical example in order to undermine the whole idea of a stable demand curve, but Hotelling recasts the problem set by Edgeworth as one of finding out the conditions under which interdependent demand curves could rule out the appearance of the 'paradox."' 
and to what extent, economists ought to work with or without the help of indifference curves in theoretical and applied demand studies.

Once he has presented the possible relationships between adjacent indifference curves, Friedman (1933, [14n5]) remarks that "from a purely abstract theoretical point of view it is impossible to set any condition whatsoever upon the indifference curves. It is only by appealing to concrete knowledge of the way individuals act, that is, to psychology, that it is possible to assert that any form of indifference curve is improbable or impossible. Mathematics, and 'pure' theory in general, can give only form, no content." Thus, Friedman is staging Pareto's methodological hesitations. On the one hand, it seems that the main simple properties could be justified by introspection (downward-sloping indifference curves, even convexity). On the other hand, more precise properties should be backed with empirical knowledge either by observation of actual behavior or by experiments (and subsequent statistical treatment of both). The respective contribution of introspection and empirical knowledge has not been established at this stage. We can even stress that the use of the word psychology in this quotation is puzzling and should be understood rather in a behaviorist sense, even though introspection is not altogether thrown away.

In brief, Hotelling, Schultz, and Friedman were the three main figures reflecting upon the relationship between the Paretian theory of demand and empirical studies of demand in the early 1930s. At the end of 1933, they felt that the introspective justification for indifference curves-the one that Pareto had recommended in the final analysis-was probably too loose and inadequate for practical needs. This idea was not yet well formed, even though they could have benefited from two attempts at experimenting on this subject. One experiment had been conducted by a well-known agricultural economist, Elizabeth Waterman Gilboy. Gilboy's (1932a) study is based on questionnaires and was regarded as a prototype for further research. The other had been conducted by a famous professor of psychology at Chicago, Louis Leon Thurstone.

In Gilboy's study, individuals were asked how many different items (travel, rent, clothes, savings, beverages, entertainment) they (and their families) would buy, with unchanged tastes and "on the basis of [their] present income and standard of living" (379), under different assumptions about income variations and price changes. Despite the call for further research, Gilboy's method would be largely ignored, probably because the use of questionnaires was severely criticized. The other way to go into experimental demand theory was to go directly into experi- 
ments on preferences, and that was precisely what was done at Chicago under the impulse of Henry Schultz.

\section{The Thurstone Experiment}

In 1930, Louis Leon Thurstone, a professor of psychology at the University of Chicago, conducted the first experiment whose goal was to construct and fit indifference curves and to show "that it is possible to write a rational equation for the indifference function which is based on plausible psychological postulates" (Thurstone 1931, 165). ${ }^{27}$ The results of his experiment were published in 1931 as "The Indifference Function" in the newly founded Journal of Social Psychology. ${ }^{28}$ Thurstone's inquiry was supposed to catch the attention of those interested in choice and demand theory.

Thurstone's motivation came from Schultz at Chicago, and his experiment was soon presented to economists at the meeting of the econometric society, in Syracuse in June 1932, under the title "An Experimental Study of Indifference Curves." A brief summary was then published in the first issue of Econometrica (Mayer 1933).

Thurstone was a colleague and friend of Schultz, and it is through their discussions that he became interested in conducting experiments on indifference curves. As he noted at the beginning of the 1931 article, "The formulation of this problem is due to numerous conversations about psychophysics with my friend Professor Henry Schultz of the University of Chicago. It was at his suggestion that experimental methods were applied to this problem in economic theory" (139).

First, we will present the ins and outs of Thurstone's experiments, stressing some aspects of his method in relation to indifference curves. Then we will appraise Thurstone's project in relation to the theory of choice.

Let us briefly present Thurstone's experiment and then make a few comments. Thurstone's article is strictly limited to the presentation of an experiment on individual preferences. Thurstone cautiously avoids appealing to the Paretian theory of choice, and the whole experiment is based upon psychological and psychophysical hypotheses that were precisely

27. Much of this section and the next deals with authors and material aptly discussed in Moscati 2007a. Nevertheless, we believe some original conclusions can be drawn from our analysis.

28. Among the founding members of the journal were John Dewey, Franklin Henry Giddings, Lucien Lévy-Bruhl, Bertrand Russell, and Thurstone himself. 
those that Pareto and Fisher wanted to eliminate. He nevertheless cites Fisher's "Mathematical Investigations" as his unique reference (aside from two articles by himself). First, Thurstone presents in its basic form the law of decreasing marginal utility, using his own terminology. He calls it the "law of satisfaction" and builds it upon Fechner's law, with the idea that each individual is able to measure quantitatively the "motivation," that is, the increase in utility, associated with an increase in the consumption of a given good. This is done by taking as a measuring rod the "discriminal error," that is, the most noticeable difference in satisfaction. ${ }^{29} \mathrm{He}$ then explains the concept of indifference curves. He arrives at the general expression of a set of indifference curves, using Fechner's law, which gives the simple Cobb-Douglas utility function (Thurstone 1931, equation 11, 147). The procedure aims at obtaining experimentally the shapes of both the satisfaction curve (indicating the increase in utility compared to an initial position) and the indifference curve, and also at fitting the indifference curves. Thus, the point is that the mathematical form of the indifference curves is given from the outset, independently from any experimental device. The only aim of the experiment is to provide enough information to derive the coefficient of motivation for each good and the level of satisfaction of the subject. The whole theoretical and experimental construction is based upon the assumption that utility is additively separable.

The experiment itself consists in asking a subject to compare two sets of two commodities, always starting from a constant combination to which another one is compared. The subject had only to tell which one he would take, thus revealing his preferences. Thurstone indicated to the subject that no economic information (notably, no budget constraint) should influence his choice. By repeating this procedure a number of times, it was possible to fill in the consumption set with minuses and pluses and to draw the experimental indifference curve associated with the constant initial combination. By repeating it again for other initial sets, it was then possible to draw four indifference curves (for hats and shoes). Then Thurstone proceeded to the same experiment with hats and overcoats and lastly with overcoats and shoes. The next step was to compare the theoretical indifference curve for overcoats and shoes (derived from Fechner's law and the first two indifference curves) with the exper-

29. More precisely, "motivation [is] the amount of anticipated satisfaction per unit increase in the commodity" (Thurstone 1931, 165), and it has been assumed "that increments in satisfaction are measured in terms of the psychological unit of measurement, the discriminal error, or multiples of that unit" (166). 
imental indifference curve..$^{30}$ Here, the most important test, according to Thurstone, was about the independence of different goods: ${ }^{31}$

Since we have the experimental data for all three sets of comparison, we can ascertain how closely the third set of indifference curves can be predicted from the known constants, derived from the first two sets of comparisons. This constitutes the test of the fundamental psychological hypothesis that is involved, namely, that the satisfactions from several commodities are summative when all of the quantities involved are above the level which the subject regards as the level of absolute necessity. (163)

The outcome of all this analysis was that indifference curves for shoes and overcoats were correctly predicted from the other experimental indifference curves, except for high constant combinations of shoes and overcoats.

At this point, a few methodological remarks are in order. They all revolve around the notion of indifference. Indeed, Thurstone raises serious doubts about the possibility of one person identifying introspectively a series of combinations of goods that he would declare indifferent to each other. Such a procedure of declared indifference, ${ }^{32}$ he argues, would be biased by a desire for numerical consistency, which is not the case with declared preference. The scientist would have to deal with too much instability. That is the reason why he resorts to the "constant method," which consists in asking a subject to declare his preferences between two combinations, one combination being always the same. Consequently, when facing two combinations, the subject was not allowed to

30. An interesting point can be made about the experimental procedure chosen: "The subject whose records are here analyzed was entirely naïve as regards the psychological problem involved and had no knowledge whatever of the nature of the curves that we expected to find" (Thurstone 1931, 154). Moreover, the experiment was carried out in such a way that the subject was unable to change his mind about his choice and that no learning could occur. Undoubtedly, this contradicts what Pareto had in mind when he wrote about indifference curves. For instance, it is not surprising that there were "inversions in responses," since the subject could make only one judgment for each pair of goods and the experiment was not carried out again. So inversions were to be expected, "especially in view of the fact that the difference in satisfaction represented by neighbouring points is not very marked" (155). Fitting was done by the method of averages, taking as data all the points in the subject's answers.

31. Obviously, independence is understood here according to the Auspitz-Lieben criterion (the second-order cross-derivatives of the utility function are zero).

32. We use the phrase "declared indifference" or "declared preference" in order to stress the methodological difference with Samuelson's theory of "revealed preference." 
declare that they were indifferent to him. Thurstone, by not allowing subjects to declare indifference, made the results of his experiment easier to process. If declared indifference had been a possible choice for the subject, Thurstone would have had to deal with indifference points and to adapt his procedure for curve-fitting.

Before we turn to the reactions of economists to Thurstone's results, it is worth stressing some methodological aspects of Thurstone's experiment that will help us appraise its usefulness for the theory of choice. First, Thurstone did not consider that each individual may be unable to reveal, even through a mental experiment, his own rational preferences (in the sense of no crossing of indifference curves). And from the outset, he even imposed very specific features on the shape of indifference curves (hyperbolic preferences). In short, Thurstone's experiment was not a device for testing some properties of rational preferences (convexity, transitivity, completeness). These properties were implemented from the beginning in the hyperbolic shape of the curves. Second, Thurstone could not ignore that the usefulness of cardinal concepts and hedonic preferences was hotly debated. And third, Thurstone did not ask whether controlled experiments were adequate for describing market behavior.

Thus, Thurstone's experiment seems to be grounded on old psychophysical hypotheses that had been rejected by the first ordinalists, and economists were rather free to interpret the results. In the final analysis, the outcome of Thurstone's experiment was to turn indifference curves into a purely psychological concept designed to illustrate the possibility of deriving rational preferences from experimental choice and to validate the set of hypotheses about the psychological continuum, about just-noticeable differences as a unit of measurement, and last, about Fechner's law.

\section{The Thurstone Experiment as Economists Saw It}

It is interesting to look at Thurstone's project from the viewpoint of economists. The Thurstone experiment received only rather critical appraisals on the part of economists and, more interestingly, it was the occasion for reintroducing the status of indifference curves within the theory of choice at the core of the debate. Broadly, Thurstone's experiment was considered as rather inconclusive, and economists raised many methodological arguments against it in the following years. The main judgment of the time was that experiments of that type were useless and inappropriate to 
the study of economic behavior. Economists only occasionally mentioned Thurstone's work, and when they did, they did so only briefly. Even among economists, it was Thurstone's work on psychological measurement rather than his experiments on indifference curves that attracted attention..$^{33}$ In general, economists were quite critical or else unconcerned or, at best, very cautious.

The main protagonists of our story referred rather coldly to the Thurstone experiment. The experiment was known first by Schultz; other economists became aware of it after Thurstone's presentation at the 1933 meeting of the econometric society in Syracuse. Among our three main characters (Hotelling, Schultz, and Friedman), only Friedman carefully examined the article and drew some methodological lessons from it (Wallis and Friedman 1942). So, it was really in the second half of the 1930s that Thurstone's experiments attracted attention.

Schultz, who can be regarded as the silent partner to the experiment, would not even comment upon the result, and made just two references to the study. The first was in Schultz 1931, ${ }^{34}$ in which he laid the foundation for statistical demand studies based upon rational behavior assumptions.

33. Thurstone's work in experimental psychology was very much praised at the time, notably his technical contributions to the measurement of individual psychological states, through multiple factor analysis (Cottrell and Gallagher 1941). Schultz (1933), commenting on Frisch's methods for measuring marginal utility, complains about the gap between the theoretical apparatus of Frisch and the experimental data and concepts used by psychologists, especially under the heading of just-noticeable differences. In Schultz 1933, Thurstone is cited as a reference but no mention is made of his experimental study of indifference. Thurstone is mentioned for his work on measurement, especially on just-noticeable differences (that is "discriminal error"): "Those who are interested in developing the border lines between economics and the other sciences will do well to investigate the relations between the methods of deriving utility and demand functions used by economists and the methods of measuring the "psychological continuum' as used by modern psychophysicists. This is not a suggestion that economics should borrow its postulates from psychology, but only that the workers in the two fields should familiarize themselves with each other's problems and procedures. While I believe that, on the whole, psychophysicists stand to gain more from such an intermarriage of ideas, I am also convinced that those statistical economists who are interested in the measurement of utility and demand cannot afford to remain in ignorance of such methods as are used to determine just-noticeable differences, and the discriminal error as a unit of measurement on the psychological continuum; for is not utility also a psychological continuum?" (Schultz 1933, 116). As regards the just-noticeable differences, Schultz mentions William Brown and Godfrey H. Thomson's Essentials of Mental Measurement (1921). As regards the measurement of the psychological continuum, he refers to Thurstone's "Psychological Analysis" (1927b) and "A Mental Unit of Measurement" (1927a).

34. "A psychological experiment designed to determine the shape of a simple indifference curve was conducted last year by the writer's colleague, Professor L. L. Thurstone, of the Department of Psychology. The results will be published in the Journal of Social Psychology for May, 1931" (Schultz 1931, 78n5). 
The second was in The Theory and Measurement of Demand (1938). The only reference there was to the title of the article (15n18).

As for Hotelling, he certainly attended the Syracuse presentation, even though we do not know whether he took part in the discussion immediately following. ${ }^{35}$ Hotelling (1938) would prove to be very cautious, and he would underline that Thurstone's experiment cannot give much more than a tentative result. Also, he clearly identified competing methods, by way of the study of family budgets:

It is to be emphasized that the indifference loci, unlike measures of pleasure, are objective and capable of empirical determination. One interesting experimental attack on this problem was made by L. L. Thurstone, who by means of questionnaires succeeded in mapping out in a tentative manner the indifference loci of a group of girls for hats, shoes, and coats. Quite a different method, involving the study of actual family budgets, also appears promising. (248; my italics)

In the same vein as Hotelling's are two other references to Thurstone's experiment. The first one is in Tintner 1942. Tintner tried to develop a dynamic theory of demand, taking into account individual expectations about future prices and interest rates. He drew conclusions about the possibility of getting information about how people anticipate and achieve an a priori probability distribution on expected prices and incomes, and he referred to Thurstone's experiment as an example of the method of questionnaires. The paper concludes with some methodological considerations: "Empirical studies of family budgets (especially historical) and of demand curves may be helpful in getting an idea about the way in which people really act. . . . The interview method may also prove useful" (304).

Another reference to Thurstone is found in Staehle 1942. Although the article is devoted to the construction of empirical cost curves, there are hints about demand theory. Staehle's criticism sounds like a farewell to the idea of experimenting beyond demand and to the possibility that experimental data can be useful:

35. It is difficult to determine who exactly attended Thurstone's presentation. We know from Joseph Mayer's (1933) report that Hotelling was present for and discussed at least the first two contributions (by Roos and by Whitman) in the same session in which Thurstone presented his paper. Frisch was the chair of the session; Mayer and Mordecai Ezekiel discussed Thurstone's results. Among other people who probably attended Thurstone's presentation were Louis H. Bean, Harold T. Davis, Dr. Roos, Harry S. Kantor, S. S. Wilks, and F. G. Crawford. See also Bercaw 1934, 402. In 1933, Thurstone presented his experiment at the meeting of the econometric society, in Syracuse, where he was criticized for wanting to measure satisfaction. 
In the study of demand, actual individual behaviour is the deepestlying level to which we can dig. Everything beyond is largely in the nature of speculation. I say largely, and not completely, remembering Thurstone's valiant attempt to measure indifference curves by means of psychological experimentation. Nevertheless, it remains true that in that field, . . . the greater part of the operation of this rationality takes place in regions where direct measurement is at least difficult. (332)

In a sense, Staehle is more skeptical about the possibility of erecting a complete theory of demand on experimental data, and all the comments by Hotelling, Staehle, and Tintner point to the weaknesses of the experimental method.

Yet, none of the comments mentioned copes with the consequences of Thurstone's experiment upon the theoretical nature of indifference curves. Among the very few references to Thurstone's experiment, the one in Georgescu-Roegen 1936 is certainly the most important, in as much as it gives clues as to why economists have rejected experimental indifference curves. Georgescu-Roegen is a centerpiece in this narrative because he deals simultaneously with the methodology of consumer theory and with the problem of integrability of consumer choice. For all that, Georgescu-Roegen's article is also sometimes muddled. The meaning of indifference curves and what can be built upon them is at the core of Georgescu-Roegen 1936 and shows once again that the ordinalist revolution did not take place without inquiring about the foundations of the new theory of the consumer. Georgescu-Roegen argues that we have to make clear what are the data that explain individual demand: "The demand and supply laws appear today to be derived concepts, and their justification is sought in terms of the ultimate considerations that find their place within the frame of economic science; i.e., the reasons that induce individuals to produce and exchange goods" (546).

After identifying sufficient assumptions for integrability, GeorgescuRoegen is led to inquire whether such assumptions can be checked by experiments. In the final analysis, he concludes that there must be a divide between what we can reasonably expect to obtain by way of experiments and what will remain necessarily of a more axiomatic nature. So, the article can be read as an inquiry into the gap between the axiomatic foundations of utility theory and the experimental design of indifference curves. Georgescu-Roegen's main conclusion is that the properties of indifference sets are given above all by mental experiments based upon introspection and abstraction. This is by necessity; this is driven by the logic of the 
problem itself: "The method of economics remains-and it seems that it will remain despite many attempts in the opposite direction - that of the mental experiment aided by introspection. There are well-known attacks directed against this procedure for supporting scientific laws. Nevertheless, we may defend our position by arguing that, so far as we deal with the consumer's position, introspection is justified by the problem itself" (546).

It is interesting to compare Georgescu-Roegen's methodological arguments with Pareto's attitude on the same question. It seems to us that Pareto regarded introspection as a sufficient procedure, given that a theoretical experiment was possible. Georgescu-Roegen is able to draw the lessons from Thurstone's experiment and from a better knowledge of the high complexity of the hypotheses that economists may need to submit to experiments, so much so that introspection is not only sufficient but also necessary for the theory of choice. Meanwhile, it would be unscientific to reject a priori any attempt at experimenting with at least some of the fundamental assumptions of the theory of choice, provided that those experiments succeed in encapsulating the essentials of the mental experiment. ${ }^{36}$ The main difficulty is precisely that experiments rarely do. Some assumptions, notably that the indifference direction at any point is uniquely determined, "are very unlikely to lend themselves successfully to [an experimental] treatment" (Georgescu-Roegen 1936, 584).

This is where Georgescu-Roegen mentions and comments on the Thurstone experiment on the nature of indifference curves:

Professor Thurstone's experiment is, however, very unlikely to help us in deciding anything about the forms of the postulates here analyzed. The investigation having been carried out by way of questions and answers, we cannot be sure whether the prices ruling on the market at the time of the experiment had or had not influenced the subjects in their answers. Some of the diagrams in Professor Thurstone's paper, namely 13 and 17, suggest on the contrary that they had.

Besides, the result of mere visualization cannot be relevant to a theory concerned with an actual choice, unless the combinations used

36. Georgescu-Roegen has in mind a kind of parallelism between mental experiments and actual experiments, provided that we recognize that not all the subtleties of our mental experiments can be captured by an actual experiment: "At the same time we may seek a safer line of approach. This might be reached, for instance, by formulating our mental experiment in such a way as to suggest, and direct step by step, the pattern of an actual experiment which may be carried out in the future, subject to technical possibilities in the matter" (Georgescu-Roegen 1936, 546). The nonintegrability case is an instance of this discrepancy, and it might be necessary to develop "an alternate theory of the nature of indifference curves" (546). 
in the experiment are those with which the subject is familiar because of his latest experience. This last condition restricts the range of the experiment to a degree which simply makes the investigation useless. It seems that we cannot avoid the necessity of letting the subject experience the satisfaction before making his choice. $(585 \mathrm{n} 3)$

Through those quotations, Georgescu-Roegen puts in the forefront the idea that the indifference curve is about stabilized preferences based on repeated acts of choice. Undoubtedly, this is the kind of argument a faithful Paretian should make against Thurstone's experiment, and it might have been very influential for the community of economists in that field. As an aside, an interesting point in this question of the essentials of mental experiments is that the experimenter must cope (1) with his own experimental difficulties (especially about the just-noticeable differences) ${ }^{37}$ and (2) with what economists have in mind when they reflect upon the stability of preferences of individuals.

In the final analysis, something evolved in the 1930s, on the issue of testing consumer theory with experiments. As the integrability issue became clarified, as the assumptions needed to relate indifference curves and index utility functions became more clearly understood, as the gap between the experimental procedures and the axiomatics of consumer theory widened, economists abandoned the idea of experimenting on indifference curves, and they let psychologists tackle the issue of which experimental procedure could adequately emulate humdrum decisionmaking in people. The opposition between two methods, one relying on experiments, the other on empirical data based on long periods of choice, emerged from all this debate.

Thus, in this period, Thurstone's experiment received rather critical comments and was never taken as a promising way to derive indifference curves and demand curves. Wallis and Friedman (1942) would deal a decisive blow on experimental indifference curves, and they would go one step beyond in questioning the conceptual foundations of the theory of choice.

37. For instance, Georgescu-Roegen proposes that there be "a unique combination $(\mathrm{Ct})$ that will separate the non-preferred from the preferred ones" (549). As he points out, "The essential implication of this postulate is that the mental comparison within a preferential set is as accurate as any other objective physical measurement can theoretically be. A perfect similarity with regard to the possibility of discerning differences in a monotonic series is thus assumed between a mental and a physical experiment" (549). Anyway, some hierarchy must be put into experimental properties of indifference functions, the most important being transitivity: "It seems that this point could be easily submitted to an experimental verification. We should really lose all hope in this direction only if the answer to such an investigation should be negative" (584-85). 


\section{The Wallis and Friedman Article}

It is worth concentrating on the Wallis and Friedman article of 1942, given that Friedman was involved from the outset in the development of demand theory through his collaboration with Schultz and Hotelling. ${ }^{38}$ The article is mainly about the relative merits of different methods for deriving empirical indifference curves and, subsequently, empirical demand curves.

Independently from each other, and then through regular discussions, Wallis and Friedman developed a systematic methodological critique of the usefulness of experimental economics in consumer theory, and even more radically, of the internal coherence of consumer theory. For this reason, the Wallis and Friedman article deserves to be read as a seminal contribution to demand theory at Chicago.

Wallis graduated in psychology and economics from Chicago and Columbia. He met Milton Friedman at Chicago in 1934, as a student of Schultz, and then went to Columbia to graduate in statistics with Harold Hotelling (Olkin 1991, 122-23). Between August 1935 and September 1937, Friedman was an associate economist together with Wallis at the National Resource Committee, where they designed questionnaires and methods of analyzing consumption (Hammond 2006). Then, during the war, Wallis was a founding member and director of the Statistical Research Group (July 1942-September 1945) (with Harold Hotelling and Jack Wolfowitz), a group of statisticians who worked on "fire quality control," that is, issues regarding the efficiency of weapons systems. ${ }^{39}$ Friedman joined the SRG as associate director. The cooperation between Friedman and Wallis certainly began at the National Resources Committee and continued after Friedman's arrival at the SRG.

For sure, the fact that Wallis earned an undergraduate degree in psychology before turning to statistics and economics made him particularly sensitive to Friedman's, Hotelling's, and Schultz's speculations on demand and especially on the possibility of inferring regular properties of individual demand patterns from rational behavior. ${ }^{40}$

The Wallis-Friedman article is entirely devoted to the derivation of indifference curves. It is based on an acknowledgment of failure: that

38. The Wallis and Friedman article is part of a book in memory of Henry Schultz.

39. "The first serious problem we had was to decide whether it would be better to have eight 50 caliber machine guns on a fighter plane or four 20 millimeter guns" (Olkin 1991, 124).

40. See especially his 1942 paper on the temporal stability of consumption patterns. 
consumer theory is grounded on and rationalized by the concept of indifference curves, whereas indifference curves are hardly ever used in any theoretical or practical study of demand, Schultz 1938 being an example of this. Wallis and Friedman advance two separate theses: (1) "The difficulties and contradictions encountered [in deriving indifference functions empirically] are ... shown to be inherent in the logical structure of the theory"; and (2) "For empirical investigations of consumer expenditures an alternative theoretical framework is required" (Wallis and Friedman 1942, 175).

From the outset, Wallis and Friedman's aim is to question the possibility of giving any empirical content to indifference curves. Indifference functions, as they put it, capture, without psychological justification, the psychological and sociological determinants of choice. Apart from its theoretical achievements (about complementarity, income and price effects, welfare criteria, and index numbers), the question raised is of "giving quantitative expression to the indifference function" (176). Before entering in detail into their argument, it must be stressed that indifference curves as they define them are embedded in strong inertial and deterministic factors (psychological and sociological), far away from any impulsive or anecdotal representation of choice. In a sense, they abide by the Paretian semantics, except that Pareto would not have let sociological determinants constrain or influence economic choices, thereby keeping economics free from nonlogical behavior.

For the first time, Wallis and Friedman make a clear distinction between two kinds of data and respectively two approaches to the problem of deriving indifference functions: (1) the experimental approach is based upon a series of data points belonging to the same indifference surfaces. (2) The "statistical" approach is based on sets of points for which the only information is the slope of the indifference surfaces at each point. Most of the paper is devoted to a critical examination of the methods and feasibility of each approach and to its sequel.

The experimental approach is quickly discarded. At first sight, the experimental approach is the more direct and can be constructed from "the application of psychophysical experimental techniques to individual subjects" (177). When they come to discussing Thurstone's experiment ("the eminent psychophysicist" [177]), they insist that the hyperbolic shape of indifference curves is predetermined by the application of Fechner's law. They carefully note that the cardinalist concepts used in the experiment have no bearing upon the result. But Thurstone's experiment cannot 
be retained as a promising way of deriving indifference curves: "The economic significance of Thurstone's experiment is vitiated by a number of serious limitations" (179).

Even though arguments against Thurstone's method are mixed, one can identify different kinds of objections. First, the experimental procedure, through comparisons of sets of goods, implies that individuals are supposed to act as if goods were free, whereas the economist is interested in choice under budget constraints. Second, the experimental procedure cannot reproduce the actual determinants of choice. This conclusion perfectly echoes the comments of Georgescu-Roegen and Staehle: there is a gap between the way in which people make choices in everyday life and what can be grasped from an experimental decision:

For a satisfactory experiment it is essential that the subject give actual reactions to actual stimuli. This requires conditions under which the reaction being studied is the only one on the basis of which the subject could produce systematic results; that is, any rationalizing scheme, conscious or unconscious, which he might adopt should have as its only possible datum the phenomenon under investigation. Questionnaires or other devices based on conjectural responses to hypothetical stimuli do not satisfy this requirement. The responses are valueless because the subject cannot know how he would react. The reactions of people to variations in economic stimuli work themselves out through a process of successive approximation over a period of time. The initial response indicates only the first step in a trial-and-error adjustment. (Wallis and Friedman 1942, 179-80)

A third argument can be raised against the experimental method. It has to do with the ceteris paribus assumption: "If a realistic experimental situation were devised, it would, consequently, be necessary to wait a considerable time after the initial application of the stimulus before recording the reaction. Even an experiment of restricted scope would have to continue for so long a period that it would be exceedingly difficult to keep "other things the same", (180).

During so long a period, it is highly unlikely that tastes and preferences would remain constant. The authors then provide a scheme of an ideally controlled experiment that would fit all the requirements for constructing indifference curves. It is based upon a psychological phenomenon about human perception: the influence of color on the apparent size of an object, a matter already studied by Wallis (1935). Yet, economic- 
type experiments are eliminated: "It is probably not possible to design a satisfactory experiment for deriving indifference curves from economic stimuli applied to human beings" (Wallis and Friedman 1942, 181). Thus, the experimental approach is irrelevant for the construction of indifference curves.

Then Wallis and Friedman tackle the statistical approach, the one Friedman 1933 was calling for. It is judged more promising than the experimental approach, even though it was also falling under similar criticism:

According to the indifference function analysis of consumer behavior, the quantities of goods purchased define a point on the indifference surfaces at which the slopes are the ratios of the prices. This suggests the possibility of using data on consumer purchases for the quantitative determination of the indifference function. The obstacle of the approach is that the function is defined for a single person at a given time. It is obviously impossible to secure more than one observation at one time, whereas many observations covering a reasonably broad segment of the function are required. If it can be assumed either that a given person has the same tastes at different times or that different persons have the same tastes at a given time, it will be possible to secure a number of observations relating to a single indifference function. Such assumptions, while never literally fulfilled, seem plausible. Certainly they seem more reasonable than those which have to be introduced in the experimental approach. They have the added merit of involving economic phenomena proper. (Wallis and Friedman 1942, 183)

Here again, limitations about the method seem to plague the construction of individual indifference functions. The period of observation must be of many years to obtain a few points; consequently, tastes cannot reasonably be considered as fixed, except maybe if there have been no important changes in the environment. So the economist is generally confronted with two equally awkward situations. Either he has a lot of observations in the neighborhood of an initial point, or he must assume that tastes have changed: "If, on the other hand, the individual has experienced a wide range of prices and incomes, his tastes have probably not remained constant, for past experience is surely one of the most important determinants of tastes at a given moment" (184).

This is certainly an idea that was not explicitly accepted by all economists of the time, and it is an important aspect of Wallis and Friedman's argument and deserves to be developed further. All in all, it is not possible 
to escape from the "alteration of preference" (184). So, the most promising procedure remains the use of data on the purchases of different individuals, belonging to groups for which the assumption of identity of preferences can reasonably be made. This assumption has to be discussed, because groups of people sharing similar tastes have usually proximate incomes, due to similar social status, cultural habits, and educational background, and they face similar prices. Once again, it will not be possible to extract enough information to construct indifference curves. Even the idea of combining observations on many individuals and for several periods seems hopeless. Either the variations of prices are slight, and then the statistical basis is narrow, or they are wide and indicate also important changes in the economic situation, so that tastes will have changed meanwhile. ${ }^{41}$

What can be kept from all this is certainly that the notion of an indifference curve is meaningful only in the neighborhood of current economic conditions and current choices for each individual (already an idea from Pareto [1909] 1971, para. 67). The only hope is to observe wide changes in prices for only a few items, compatible with "the assumption of unaltered tastes and with fairly rapid adjustment to the price changes," so that it is possible to obtain "a fairly satisfactory derivation of indifference surfaces for a subset of goods" (Wallis and Friedman 1942, 185). To sum up the pessimistic results,

While it is thus entirely impossible to obtain indifference surfaces from market data, it seems highly unlikely that reliable results can be obtained for more than a small range of quantities for a few goods. The necessity of using data that reflect reactions to essentially the same indifference function implies a serious limitation on the degree of income and price variation that can be observed and hence in the scatter of points on which the indifference surfaces can be based. If these points cover a wide range, it is unlikely that they relate to the same system of indifference surfaces; if they cover a narrow range,

41. Abraham Wald (1940) showed how to approximate an index-utility function described by a polynomial of the second degree in goods from Engle curves (linearized in a small region of the commodity space), and he had raised both the integrable and nonintegrable case, wondering about the practical feasibility of this procedure. Especially, he raised doubts about the method because "not all individuals have exactly the same scale of preferences, the individuals do not choose exactly the set of goods for which the indicator has the greatest value, the goods compared in different periods are not exactly of the same quality, and so on" (148). $\mathrm{He}$ ended with the nonintegrability case. In this case, the assumption that indifference surfaces did not change during the period of observation was rejected (175). 
the indifference surfaces derived from them will be subject to wide margins of errors and to statistical instability. (185-86)

In the final analysis, Wallis and Friedman's main thesis is that however one tries to match statistical data with the concept of the indifference curve, it will be unsuccessful. The problem, as they see it, comes from the fact that the indifference curves have been constructed theoretically upon a supposed categorization of economic phenomena within three sets: tastes, opportunity, and goods. Wallis and Friedman show that the same thing (e.g., regional location, family size, and probably income) can be classified either into the first, the second, or the third, so that it is practically impossible to use any statistical data to construct indifference curves: "The ambiguity of the classificatory criteria which are implicit in indifference curve analysis is, of course, the reason it is so difficult to specify reasonable data. Satisfactory data can be obtained only if opportunity factors vary over a wide range while taste factors remain constant; but this is clearly impossible because the opportunity factors and the taste factors are inextricably interwoven-are really the same factors under different aliases" (187-88).

So the only useful work to be done is to abandon indifference curves, which are of no use "for the organization of empirical data" (189), as an intermediary object to demand analysis and to adopt a more direct approach and to infer from statistical data which factors do influence, and to what extent, current consumption (income, regional location, age, etc.): "There is much to be gained by concentrating some heavy theoretical artillery on the logical structure implicit in the practical work" (189).

It is beyond the scope of the present study to inquire into the general approach to demand theory advocated by Friedman and Wallis. It has often been remarked that their article shares some methodological principles with other members of the Chicago school (Knight 1944; Stigler 1939) and that it contains the seeds of Friedman's (1949) famous article on the demand curve. It remains to be shown whether this episode can help to clarify the methodological principles of Friedman's demand theory (Mongin 2000a). We will not develop this point further.

Two final remarks can be made on the Wallis and Friedman article. First, it is clearly organized as a systematic attack on the foundations of the theory of choice. It begins with a regular criticism of experimental or empirical foundations of indifference curves on the basis of a Paretian definition of indifference curves. Once that work has been done, the next step in Wallis and Friedman's strategy is to question the interest of the 
theory itself. Second, Wallis and Friedman stipulate implicitly that any theoretical concept must have empirical content. So, they reject indifference curves on the ground that they are poorly adapted to empirical data. This is clearly at odds with the line of thought that emerged in GeorgescuRoegen's article and that had just been exemplified in Samuelson's revealed preference theory.

\section{Samuelson's Revealed Preferences and the Status of Indifference Curves}

In contrast with Wallis and Friedman's destructive criticism of the concept of the indifference curve and ultimately of the Paretian theory of choice, we have the other criticism of the concept, as it was first raised by Samuelson through the revealed preference approach. Our main point in this section is that Samuelson's criticism legitimized the concept of indifference curves as a heuristic device.

As is now well known, Samuelson (1938a, 1938c) was at first critical of the Hicks-Allen hypothesis of a diminishing marginal rate of substitution. After the introduction of the strong axiom of revealed preferences (Houthakker 1950), Samuelson came to recognize that the SlutskyHicks-Allen approach and the revealed preference approach arrived at the same set of analytical statements, ${ }^{42}$ so that a rational consumer could be represented equivalently as a utility maximizer or as behaving according to a set of axioms (Mongin 2000b; Chipman and Lenfant 2002). Meanwhile, it is interesting to examine Samuelson's comments upon the concept of indifference curves, because Samuelson has always pointed out that it remains a concept that exists only as a conjecture external to the revealed preference approach.

In the following, we claim that Samuelson consistently stressed the topic of the status of indifference curves (and of the mere idea of indifference) all along his breakthrough from the first articles on revealed preferences (Samuelson 1938a, 1938b, 1938c) up to the final 1950 article on the question of integrability. Samuelson's approach to demand behavior was based on observed choice and upon a principle of revelation of preferences. The most important consequences, for our subject, are (1) that Samuelson dispensed with the concept of indifference curves in favor of that of preferred choice and (2) that indifference curves could be obtained, at best

42. Except for a full understanding of the discrete analogue to Slutsky symmetry conditions and positive semi-definiteness of the Slutsky matrix (Chipman and Lenfant 2002, 577-78). 
indirectly, if they should be obtained at all. In the end, Samuelson did not reject the concept but, rather subtly, limited its role to that of a heuristic device. It is interesting to note first that Samuelson's interest in the theory of choice originated in a criticism of the (widespread) use of indifference curves and index numbers in economic theory. ${ }^{43}$ It is necessary also to understand that Samuelson wanted to establish a comprehensive comparison between the traditional theory and his revealed preference approach, and that at the same time he was conscious that too narrow a comparison might lead to misleading terminological convergence.

A brief overview of the development of Samuelson's ideas will help clarify the difference between the indifference curve approach and the revealed preference approach. ${ }^{44}$ Samuelson $(1938 c, 61)$ regarded the HicksAllen (1934) replacement of a utility function with the concept of the decreasing marginal rate of substitution ${ }^{45}$ as an incomplete theoretical achievement, as it still depended on psychological assumptions. A true positivist theory of choice, as he put it, should rely upon observable choices only and thus should be deprived of such "vestigial traces of utility." Thus, the aim of the revealed preference approach was to identify a set of axioms necessary and sufficient "for most of the empirical meaning of the utility analysis" (Samuelson 1938a, 353). ${ }^{46}$ Yet, Samuelson did not identify

43. "We are now in a position to complete the programme begun a dozen years ago of arriving at the full empirical implications for demand behaviour of the most general ordinal utility analysis. My own work in this direction grew out of a remark made to me by Professor Haberler in his 1936 international trade seminar at Harvard. 'How do you know indifference curves are concave?' My quick retort was 'Well, if they're not, your whole theory of index numbers is worthless.' Later I got to thinking about implications of this answer (disregarding the fact that it is not worded quite accurately). Being then full of Professor Leontief's analysis of indifference curves, I suddenly realized that we could dispense with almost all notions of utility: starting from a few logical axioms of demand consistency, I could derive the whole of the valid utility analysis as corollaries" (Samuelson 1950, 369-70).

44. For an analytical and methodological discussion of Samuelson's revealed preferences, see Mongin 2000b and Chipman and Lenfant 2002.

45. In the rest of this article, we adopt Hicks's revised terminology of "decreasing marginal rate of substitution" and "convex" indifference field even though Samuelson kept Hicks and Allen's original terminology of "increasing marginal rate of substitution" and "concave" indifference field.

46. Samuelson's approach is clearly in accordance with the Paretian semantics of choice. He is concerned with "long run 'normal' behaviour" only (Samuelson 1950, 360). He also makes it clear that the internal experiments of the consumer are of no interest for the problem of integrability, and he states, as Pareto did, that any observed choice can be regarded "as a steady flow of consumption per unit time, optimally patterned to the consumer's tastes. And the flow of consumption at B is again a steady flow long maintained. The comparison of $A$ and $B$ (and of intermediate points) is a case of comparative statics" (361). So, the economist need not invade the consumer's privacy. 
at once what exactly in the Hicks-Allen approach was supporting the psychological assumption. In addition, he did not mean that the traditional analysis in terms of utility and indifference curves was deprived of any analytical advantage. Consistently, Samuelson (1938b) would pursue at the same time the analysis of the revealed preference approach and the analysis of the traditional utility/indifference curve approach. Those parallel endeavors aimed at stressing the relative merits of each theoretical basis for demand analysis and, incidentally, at clarifying the status of indifference curves within each. The most significant article regarding the status of indifference curves within the revealed preference approach was the 1948 article, in which Samuelson dealt frontally with the possibility of obtaining indifference curves as the result of a limit process. In that article, he commented upon Ian Little's proof that "if enough judiciously selected price-quantity situations are available for two goods, we may define a locus which is the precise equivalent of the conventional indifference curve" (Samuelson 1948, 243) and presented an alternative demonstration. Finally, the 1950 article on integrability provided a comprehensive analysis of the qualitative differences between the utility approach and the revealed preference approach. Once the weak axiom of revealed preference was replaced with the strong axiom, the analytical differences between both approaches were considerably smoothed, and Samuelson stressed the main implications for the concept of indifference curves.

With this theoretical development in mind, we will examine more precisely the impact of the Samuelsonian program upon the concept of indifference curves. The axioms of revealed preference were designed in relation to the theory of index numbers and were especially adapted to empirical research, as they were conceived in terms of finite variations and not in terms of differentials. The outcome of all this was that Samuelson obtained the same results as did Hicks and Allen, and the only argument in favor of the revealed preference approach was mainly methodological: "The orientation given here is more directly based upon those elements which must be taken as data by economic science, and is more meaningful in its formulation" (Samuelson 1938c, 71).

Echoing this methodological position, Samuelson consistently remained reluctant to use the term indifference curve or indifference surface. Given that his rationality axioms were entirely formulated in terms of preferences, indifference curves could be at best obtained by describing the whole space of preferences. There was nothing in the indifference curves so obtained that could not have been obtained from data on properly 
selected choices. Conversely, observations on choices being the only data on which to base the construction of indifference curves, those data would never allow us to reveal those parts of the indifference complex that were concave to the origin, because no choice would ever be observed on those parts. So revealed preferences captured all the market data necessary to construct an indifference curve and at the same time they captured nothing more than what was obtainable from market behavior. Under that double constraint, Samuelson carefully examined the status of indifference curves within the governance of revealed preferences.

Samuelson and others were precisely pointing out the obstacles to the derivation of an indifference curve from a finite number of observations. Little (1949) had shown that a selection of price-quantity situations and corresponding choices might be enough to "define a locus which is the precise equivalent of the conventional indifference curves" (Samuelson 1948, 243). ${ }^{47}$ Samuelson (1948) showed how to obtain the same result through a Cauchy-Lipschitz process of approximating the supposed indifference curve from below. The argument ran as follows. On the basis of the axiom of revealed preference, if the consumption set could be filled with data on observed choices at any point $(x, y)$ desired, it was thus possible to integrate the differential equation linking little slope elements (d $y / \mathrm{d} x$ ) to a function $f(x, y)$ that was equal to the ratio of the prices $p_{x} / p_{y}$ at any point. The solution to the equation $\mathrm{d} y / \mathrm{d} x=f(x, y)$ was shown to be precisely the "conventional" indifference curves.

It must be clear that nowhere did Samuelson suggest that the axioms of revealed preferences could be used to reveal indifference. Indifference could only be revealed after a certain kind of mathematical treatment

47. A comparative analysis of Little's and Samuelson's contributions to revealed preferences is beyond the scope of this article. In my view, Samuelson's approach is deliberately oriented toward clarifying the relationships with the traditional ordinalists' approach; Little, on the contrary, is much more interested in the implications of the new approach for the theory of index numbers. Little's (1949) contribution to the debate is quite important (his article was written before Samuelson 1948). It contains the central idea and method for constructing step-by-step a "behaviour line." Little's approach differs from that of Samuelson in two respects. First, the departure point is a comparison between welfare criteria based upon index numbers and based upon indifference curves. Second, it is directly critical of the concept of indifference curves. Little's main idea is to dispense with indifference curves and to inquire whether a series of points can be found, using a transitive property of consistent behavior, so that the index-number criterion of welfare improvement should "tell the same story" as the indifference curve criterion. In the end, "the concept of indifference is abandoned" (Little 1949, 91). Surely, Little's discussion of the meaning of "preference" and "choice" deserves more attention than it has received so far. 
implying differential calculus and necessitating a potentially infinite amount of information of the revealed-preference type. "Any CauchyLipschitz path always leads to a final point worse than the initial. And strictly speaking, it is only as an infinite limit that we can hope to reveal the neutral case of 'indifference' along the true solution curve to the differential equation" (Samuelson 1948, 248; my italics). This was not yet enough to speak of an "indifference curve." What we had was just a set of points revealed to be worse than a certain point A. In terms of the strict algebra of "revealed preferences" we had as yet no definition of what was meant by "equality" or "indifference" (248). So, in order to assign the name "indifference curves" to the loci of points described by the differential equation, it was necessary to prove that "all points above the true mathematical solution [were] definitely 'revealed to be better' than A" (248). This was done through providing a process of approximation from above, similar to the Cauchy-Lipschitz solution. The unique curve lying between both approximations was the "behaviour line" of Little, and "we may care to give this contour line, by courtesy, the title of an indifference curve" (248; my italics). ${ }^{48}$

Once again, one can consider how reluctant Samuelson was to use the word indifference in the framework of the revealed preference approach. Our interpretation for this is that Samuelson believed that the term indifference curve could divert people from the behaviorist foundations of such a curve and make them think that indifference curves could be obtained directly through nonmarket experiments in spite of being revealed. Again in the 1950 article on integrability, the behaviorist nature of the data was the real frontier between the terminology of indifference and that of revealed preference: there was nothing like revealed indifference. There he drew a figure with indifference curves, some of which were partly concave to the origin. And on the other figure, he drew little slope elements corresponding to the convex parts only: "It will be noted that any point where the indifference curves are [concave] rather than [convex] cannot be observed in a competitive market. Such points are shrouded in eternal darkness" (Samuelson 1950, 359). In that case, only a monopsonist could bend the budget curve so as to make it possible to reveal some (but not all) the points in a concave portion of his preference field. And precisely non-

48. Or later: "If we wish, then, we may speak of them as being indifferent to A. The whole theory of consumer's behaviour can thus be based upon operationally meaningful foundations in terms of revealed preference" (Samuelson 1948, 251). 
market experiments were of this type, completely opposite to the perfect competition framework which was supposed in the theory of choice and which had to serve as a basis for the theory of demand and aggregate demand: ${ }^{49}$ "The case of a Gallup-poll questioner who finds out the man's preference contours by giving him choices of every pair of goods is simply a limiting case of monopsony. And if we experiment sufficiently, we can always find a curved family of unique contours representing his ordinal preference field-if such a consistent field exists" (361).

To conclude this discussion of Samuelson's reconstruction of indifference, we would like to make two points.

Samuelson stressed that indifference curves are not a direct result of controlled experiments; they can only be obtained, if ever they can be obtained, through an indirect process of describing the field of preferences of a given consumer, under different situations of choice under budget constraints. Consequently, Samuelson remained reluctant to deal with indifference curves, because they were methodologically deceptive, giving the false impression of a theoretical (positivist) progress compared with the old utility theory, whereas they could also convey psychological assumptions. So, indifference curves conveyed a "dangerous terminology" (Samuelson 1950, 365). Nevertheless, Samuelson did not go as far as rejecting de facto the use of indifference curves, provided that one was clearly warned about the methodological fragility of the concept.

Second, Samuelson, echoing Georgescu-Roegen (1936), rejected the idea that indifference curves could be determined through experimentation. But contrary to common bottom-up criticism (criticism stressing the difficulty of constructing experimental indifference curves), his criticism stemmed directly from the idea that in a competitive framework at least, the economic facts one would use were acts of choice under budget constraints, so that other kinds of experiments were ruled out from the outset. A connected question, nevertheless, was about the possibility of practically running experiments on subjects facing budget constraints. My point

49. Here, Samuelson seems to be less stringent in his interpretation of indifference curves, because he implicitly accepts that an experiment should allow the scientist to capture the whole preference field. This is at odds with other statements in the same articles. "Therefore, in this generalised monopsony we can behaviouristically identify the man's ordinal preference field if it has one" (Samuelson 1950, 361). Years later, Samuelson recalled this advantage of the revealed preference approach as a general methodology, to the effect that the strong axiom of revealed preference can imply "valid relations applicable to admissible specifications of non-convex sets" (Samuelson 1998, 1381). 
is that Samuelson seemed to agree essentially with the Paretian semantics of indifference curves. That is, indifference curves were supposed to represent market choices under stabilized economic behaviors, after a period in which decisions were made on a trial-and-error basis. It was only then that a consistent indifference curve could be, at best, approximated. Thus, it is reasonable to infer from this that for Samuelson, it was practically impossible to carry out experiments on indifference curves compatible with the Paretian semantics. Consequently, if the concept of the indifference curve was to have any legitimacy, it would be just as a tool for ordering our knowledge about economic behaviors. ${ }^{50}$ As such, indifference curves were useful for their heuristic and pedagogical properties, since they could help us organize our ideas and data on individual choices. ${ }^{51} \mathrm{~A}$ connected result was that practical studies based on indifference curves should involve checks as to whether data on market behaviors were strong enough to guarantee a convex structure of tastes.

\section{Conclusions}

The aim of this article was to shine some light on a methodological debate about the exact nature of indifference curves underlying the foundations of the theory of choice. The main lesson to be drawn from the debate is that adopting the index-utility function was not a sufficient foundation on which to erect the new theory of choice. The adoption of an ordinal conception of utility had to be accompanied by a common language about the methodological foundations of the theory. All this debate was nascent in Pareto's works, where he seemed to hesitate about the experimental status of indifference curves. It was settled step-by-step in the 1930s and 1940s. Two major attitudes emerged from the debate. On the one side, there was Samuelson's revealed preference approach, which captured the essentials of the idea that indifference curves were useful for organizing our ideas about demand behavior, even though they were not likely to be obtained

50. One may be inclined to consider also that Samuelson shows a sentimental attachment to the concept since it was an important step in the development of ordinalism. I prefer to consider that Samuelson retained indifference curves as something useful (see Samuelson 1974).

51. To be sure, the widespread use of indifference curves as a heuristic and pedagogical tool would be naturally reinforced by the simple fact that we can only use indifference curves to analyze choices involving two or three goods. It does not allow one to deal with utility defined over more than three goods. This supplementary explanation is but a negative justification for relegating indifference curves to microeconomics textbooks, whereas the Samuelsonian argument is rather a positive justification for this. 
practically through experiments. On the other side, Wallis and Friedman's approach rejected the theory of choice on the grounds that it was badly suited to any kind of empirical data, and they called for other foundations directly grounded on facts. On the way toward this deepening of the theory of choice, we saw that the vast majority of economists concerned commented rather scantily on Thurstone's attempt. The reluctance toward experimenting on individual preferences was strong enough to make later attempts very rare. Within consumer choice theory (choice under certainty), only two other experiments with indifference curves seem to have been conducted since Thurstone's experiment (Rousseas and Hart 1951; and MacCrimmon and Toda 1969).$^{52}$ Indeed, it is reasonable to think that from the 1940s onward economists were not much interested in obtaining such curves.

Before coming to a more general conclusion about the orientation that would be given to the foundations of the theory of choice, we can draw some specific conclusions about our story.

First, Thurstone's experiment must be appraised carefully. From the reading of his article in the Journal of Social Psychology, it is reasonable to infer that Thurstone's experiment was first designed to answer questions that were under debate within the community of psychologists and not within that of economists. The central question behind Thurstone's experiment was the existence of what he called a "psychological continuum" and of a unit of measurement for individual satisfaction. In fact, the article does not contain any reflection about the meaning of preferences or the best way to obtain those preferences or to make sure that those preferences are stable and not affected by external factors or by the experimental process. It was left to economists, through their comments, to appraise the possibility and the interest for the theory of choice of such experiments.

Second, one of the consequences of the debate about the status of indifference curves was Wallis and Friedman's radical criticism of the theory of choice. This radical criticism meant to get rid of the foundations of consumer theory and called for a new logical structure of consumer theory. This may help to organize our ideas about further unorthodox developments in the theory of demand and choice. It would be worth it to see to what extent work from Knight, Friedman, Becker, Lancaster, and others address Wallis and Friedman's recommendations. 
Third, Samuelson's approach to the status of indifference curves has proved to be fruitful. Samuelson's criticism was based mainly on the same principles as Friedman's, but it was not aimed at getting rid of the theory. On the contrary, it was aimed at unveiling the legitimate uses of indifference curves within demand and choice theory. We have shown that it possible to read Samuelson's work on revealed preferences by focusing on the meaning of the word indifference. Samuelson wanted to match two contrasting attitudes. On the one hand, he subscribed to a positivist methodology, by which he was led to privilege a definition of theoretical terms as observables, which, together with axioms of choice, would allow one to derive operationally meaningful theorems. On the other hand, he remained skeptical about the practical possibility of conducting experiments or obtaining data that would be reliable and precise enough to falsify or corroborate an operationally meaningful theorem. The fact is that because Samuelson was more stringent than Pareto in promoting a positivist approach to choice, his skeptical attitude was apparent on many more occasions. Quite logically, it was only through the evolution of the theoretical program that he tempered his reservations against utility theory. Thus, the bulk of the revealed preference approach regarding the nature of indifference curves would condense progressively, and the quintessence of it could be found in the 1950 article, once the main implications of the revealed preference approach were known (after Houthakker's introduction of the strong axiom of revealed preferences). ${ }^{53}$

A more speculative conclusion, calling for further inquiry, can be drawn from this story. It deals, broadly speaking, with the internal relationships between economics, psychology, and experimentation. Our claim is that the criticisms raised against naive attempts at doing experiments on preferences considerably clarified the proper use of indifference curves as a useful tool for economic theory, and by so doing also made possible a deeper questioning of the meaning of indifference. There were now favorable conditions for a quiet interplay between economics and psychology. By, say, the end of the 1940s, it had become possible to question the inter-

53. Otherwise stated, the status of indifference curves could not be clarified as long as the analytical problem of integrability remained unsettled. This is in accordance with Mongin's (2000b, 1127) claim that the relationship between the revealed preference approach and integrability is first and foremost a technical issue. Our reading of revealed preference theory in relation to indifference curves reinforces Mongin's claim that Samuelson did not want to eliminate traditional utility theory. Nevertheless, it also shows that empirical workers in the field of demand shall not be exempted from being cautious when they resort to this concept. 
nal meaning of preferences. Many instances of such interplay can be seen in the economic literature (see Moscati 2007a). Georgescu-Roegen (1950) laid down the foundations for a stochastic theory of choice (under certainty). Binary choice and transitivity became a common field for experiments and theorization for economists and psychologists (May 1954; Quandt 1956). More generally, before the 1940s economists rarely distinguished between descriptive and normative theories, but by the 1950s, such a distinction had become almost systematic. Thus, it is quite reasonable to think that the main outcome of the debates on the status of indifference curves was to put on firmer ground the idea that economists might gain something from cooperating with psychologists, because the latter offered a better understanding of the kind of questions economists wished to address: What makes it impossible to unveil preferences? What are the consequences of making binary choices in the absence of knowledge of additional possibilities? To what extent do people discover their own preferences through learning? Does this necessarily imply that intransitivity will be the rule?

\section{References}

Allen, Roy G. D. 1932. "The Foundations of a Mathematical Theory of Exchange.” Economica 12:197-226.

- 1934. "The Nature of Indifference Curves." Review of Economic Studies 1 (February): 110-21.

Bercaw, Louise O. 1934. "Price Analysis: Selected References on the Theoretical Aspects of Supply and Demand Curves and Related Subjects.” Econometrica 2 (4): 399-421.

Brown, William, and Godfrey H. Thomson. 1921. The Essentials of Mental Measurement. Pt. 1. Cambridge: Cambridge University Press.

Boring, Edwin G. 1950. A History of Experimental Psychology. 2nd ed. New York: Appleton-Century-Crofts.

Bruni, Luigino, and Francesco Guala. 2001. "Vilfredo Pareto and the Epistemological Foundations of Choice Theory." HOPE 33 (1): 21-49.

Chipman, John S. 1976. "The Paretian Heritage," Revue européenne des sciences sociales, et cahiers Vilfredo Pareto 14 (37): 65-173.

Chipman, John S., Leonid Hurwicz, Marcel K. Richter, and Hugo F. Sonnenschein, eds. 1971. Preferences, Utility, and Demand. New York: Harcourt Brace Jovanovich.

Chipman, John S., and Jean-Sébastien Lenfant. 2002. "Slutsky's 1915 Article: How It Came to Be Found and Interpreted." HOPE 34 (3): 553-97.

Cottrell, Leonard S., Jr., and Ruth Gallagher. 1941. "Important Developments in American Social Psychology during the Past." Sociometry 4 (3): 302-24. 
Darnell, Adrian C. 1990. "The Life and Economic Thought of Harold Hotelling." In The Collected Economics Articles of Harold Hotelling, edited by Adrian C. Darnell, 1-28. New York: Springer Verlag.

Edgeworth, Francis Ysidro. 1881. Mathematical Psychics. London: C. Kegan Paul. Fanno, Marco. 1926. "Contributo ala teoria matematica delle beni succedani." Annali di economia 2:329-471.

1933. "Interrelation des prix et courbes statistiques de demande et d'offre." Econometrica 1 (2): 162-71.

Fisher, Irving. 1892. "Mathematical Investigations in the Theory of Value and Prices." Transactions of the Connecticut Academy 9 (July): 1-124.

Friedman, Milton. 1933. "The Fitting of Indifference Curves as a Method of Deriving Statistical Demand Curves." Manuscript.

_. 1949. "The Marshallian Demand Curve." Journal of Political Economy 57 (6): 463-95.

Frisch, Ragnar. 1926. "Sur un problème d'économie pure." Norsk mathematisk skrifter, ser. 1, 16:1-40.

- 1932. New Methods of Measuring Marginal Utility. Tübingen: Mohr.

Georgescu-Roegen, Nicholas. 1936. "The Pure Theory of Consumer's Behavior." Quarterly Journal of Economics 50 (4): 545-93.

- 1950. "The Constancy of Choice and the Constancy of Economic Laws." Quarterly Journal of Economics 64 (1): 125-38.

Gilboy, Elizabeth Waterman. 1932. "Demand Curves by Personal Estimate.” Quarterly Journal of Economics 46 (2): 376-84.

Giocoli, Nicola. 2003. Modeling Rational Agents. Cheltenham: Elgar.

Green, Edward J., and Keith A. Moss. 1993. "The Reorientation of Neoclassical Consumer Theory." In Scientific Failure, edited by T. Horowitz and A. I. Janis, 49-78. Lanham, Md.: Rowman \& Littlefield.

Gross, Martin, and Vincent J. Tarascio. 1998. "Pareto's Theory of Choice." HOPE 30 (2): 171-87.

Hammond, J. Daniel. 2006. "More Fiber Than Thread? Evidence on the MirowskiHands Yarn." In Agreement on Demand: Consumer Theory in the Twentieth Century, edited by Philip Mirowsi and D. Wade Hands. HOPE 38 (supplement): 130-52.

Hands, D. Wade. 1993. "More Light on Integrability, Symmetry, and Utility as Potential Energy in Mirowski's Critical History.” In Non-natural Social Science: Reflecting on the Enterprise of "More Heat Than Light," edited by Neil de Marchi. HOPE 25 (supplement): 118-30.

—. 2006. "Integrability, Rationalizability, and Path Dependency in the History of Demand Theory." In Agreement on Demand: Consumer Theory in the Twentieth Century, edited by Philip Mirowsi and D. Wade Hands. HOPE 38 (supplement): 153-85.

Hands, D. Wade, and Philip Mirowski. 1998. "Harold Hotelling and the Neoclassical Dream.” In Economics and Methodology, edited by Roger E. Backhouse, Daniel M. Hausman, Uskali Mäki, and Andrea Salanti, 323-97. Basingstoke: Palgrave Macmillan. 
Hicks, John R., and Roy G. D. Allen. 1934. "A Reconsideration of the Theory of Value.” Pts. 1-2. Economica, n.s., 1 (February): 52-76; 1 (May): 196-219.

Hotelling, Harold. 1932. "Edgeworth's Taxation Paradox and the Nature of Demand and Supply Functions.” Journal of Political Economy 40 (5): 577-616.

- 1938. "The General Welfare in Relation to Problems of Taxation and of Railway and Utility Rates." Econometrica 6 (July): 242-69.

Houthakker, Hendrik S. 1950. "Revealed Preference and the Utility Function." Economica, n.s., 17 (66): 159-74.

Johnson, William Ernest. 1913. "The Pure Theory of Utility Curves." Economic Journal 23 (December): 483-513.

Knight, Frank. 1944. "Realism and Relevance in the Theory of Demand." Journal of Political Economy 52:289-318.

Lachelier, Henri. 1885. "Les lois psychologiques dans l'école de Wundt." Revue philosophique de la France et de l'étranger 19:121-46.

Lange, Oskar. 1934. "The Determinateness of the Utility Function." Review of Economic Studies 1 (3): 218-25.

Lenfant, Jean-Sébastien. 2000. "La substituabilité dans la théorie de la demande et des prix." PhD diss., University of Paris 1.

- 2006. "Complementarity and Demand Theory: From the 1920s to the 1940s." In Agreement on Demand: Consumer Theory in the Twentieth Century, edited by Philip Mirowski and D. Wade Hands. HOPE 38 (supplement): 48-85.

Lenoir, Marcel. 1913. Etudes sur la formation et le mouvement des prix. Paris: Giard \& Brière.

Lewin, Shira B. 1996. "Economics and Psychology: Lessons for Our Own Day from the Early Twentieth Century." Journal of Economic Literature 34:1293-1323.

Little, Ian M. D. 1949. "A Reformulation of the Theory of Consumer's Behaviour." Oxford Economic Papers, n.s., 1 (1): 90-99.

MacCrimmon, Kenneth R., and Masanao Toda. 1969. "The Experimental Determination of Indifference Curves." Review of Economic Studies 36 (4): 433-51.

Marshall, Alfred. (1890) 1898. Principles of Economics. 4th ed. London: Macmillan.

May, Kenneth O. 1954. "Intransitivity, Utility, and the Aggregation of Preference Patterns." Econometrica 22:1-13.

Mayer, Joseph. 1933. "The Meeting of the Econometric Society in Syracuse, New York, June 1932.” Econometrica 1 (1): 94-104.

Mongin, Philippe. 2000a. "La méthodologie économique au XXe siècle: Les controverses en théorie de l'entreprise et la théorie des préférences révélées." In Nouvelle histoire de la pensée économique, edited by Alain Béraud and Gilbert Faccarello, 340-78. Paris: La Découverte.

—.2000b. "Les préférences révélées et la formation de la théorie du consommateur." Revue économique 51 (September): 1125-52.

Morrow, Glenn R. 1930. Review of Essays in Philosophy, by Seventeen Doctors of Philosophy of the University of Chicago; edited by T. V. Smith and W. K. Wright. Journal of Philosophy 27 (8): 218-22.

Moscati, Ivan. 2007a. "Early Experiments in Consumer Demand Theory: 1930-1970." HOPE 39 (3): 359-401. 
2007b. "History of Consumer Demand Theory, 1871-1971: A Neo-Kantian

Rational Reconstruction.” European Journal of Economic Thought 14 (1): 119-56. Olkin, Ingram. 1991. “A Conversation with W. Allen Wallis." Statistical Science 6 (2): 121-40.

Ormazabal, Kepa M. 1995. "The Law of Diminishing Utility in Alfred Marshall's Principles of Economics." European Journal of the History of Economic Thought 2 (1): 91-126.

Pareto, Vilfredo. 1896-97. Cours d'économie politique. Lausanne: F. Rouge.

- 1900. "Sunto di alcuni capitoli di un nuovo trattato di economia pura del Prof. Pareto." Giornale degli economisti, 2nd ser., 20 (March): 216-35; (June): 511-49.

(1900) 2008. "Summary of Some Chapters of a New Treatise on Pure Economics by Professor Pareto." Translated by John S. Chipman. Giornale degli economisti e annali di economia 67 (3): 453-504.

_. (1909) 1971. Manual of Political Economy. Translated by Ann S. Schwier.

New York: Augustus M. Kelley.

Quandt, R. E. 1956. "Probabilistic Theory of Consumer Behavior.” Quarterly Journal of Economics 70:507-36.

Rousseas, Stephen W., and Albert G. Hart. 1951. "Experimental Verification of a Composite Indifference Map." Journal of Political Economy 59 (4): 288-318.

Samuelson, Paul Anthony. 1938a. "An Addendum [to "A Note on the Pure Theory of Consumer's Behaviour'].” Economica, n.s., 5 (August): 353-54.

— 1938b. "The Empirical Implications of Utility Analysis." Econometrica 6:344-56.

1938c. "A Note on the Pure Theory of Consumer's Behaviour." Economica, n.s., 5 (February): 61-71.

- 1948. "Consumption Theory in Terms of Revealed Preference." Economica,

n.s., 15 (November): 243-53.

1950. “The Problem of Integrability in Utility Theory.” Economica, n.s., 17

(November): $355-85$.

. 1974. "Complementarity: An Essay on the 40th Anniversary of the Hicks-

Allen Revolution in Demand Theory." Journal of Economic Literature 12:1255-89.

. 1998. "How Foundations Came to Be." Journal of Economic Literature 36

(September): 1375-86.

Schultz, Henry. 1931. "The Italian School of Mathematical Economics.” Journal of Political Economy 39 (1): 76-85.

- 1933. "Frisch on the Measurement of Utility." Journal of Political Economy 4:95-116.

- 1938. The Theory and Measurement of Demand. Chicago: University of Chicago Press.

Schumpeter, Joseph A. 1954. History of Economic Analysis. New York: Oxford University Press.

Slutsky, Eugen. 1915. "Sulla teoria del bilancio del consumatore." Giornali degli economisti e rivista di statistica, 3rd ser., 51 (July): 1-26. 
Staehle, Hans. 1942. "The Measurement of Statistical Cost Functions: An Appraisal of Some Recent Contributions." American Economic Review 32 (2): 321-33.

Stigler, George J. 1939. "The Limitations of Statistical Demand Curves." Journal of the American Statistical Association 34 (207): 469-81.

- 1950. "The Development of Utility Theory." In Essays in the History of Economics. Chicago: University of Chicago Press.

Thurstone, L. L. 1927a. "A Mental Unit of Measurement.” Psychological Review 34 (6): 415-23.

. 1927b. "Psychological Analysis." American Journal of Psychology 38 (July): 368-89.

. 1931. "The Indifference Function.” Journal of Social Psychology 2:139-67.

Tintner, Gerhard. 1942. "A Contribution to the Non-static Theory of Choice." Quarterly Journal of Economics 56 (2): 274-306.

Wald, Abraham. 1940. "The Approximate Determination of Indifference Surfaces by Means of Engel Curves.” Econometrica 8 (2): 144-75.

Wallis, W. Allen. 1935. "The Influence of Color on Apparent Size." Journal of General Psychology 13:193-99.

1942. "The Temporal Stability of Consumption Patterns." Review of Economics and Statistics 24 (4): 177-83.

Wallis, W. Allen, and Milton Friedman. 1942. "The Empirical Derivation of Indifference Functions." In Studies in Mathematical Economics and Econometrics: In Memory of Henry Schultz, edited by Oscar Lange, F. McIntyre, and T. O. Yntema, 175-89. Chicago: University of Chicago Press.

Wong, Stanley. 1978. The Foundations of Paul Samuelson's Revealed Preference Theory. London: Routledge. 
